\title{
Redefining and Extending the Scope of System Development Life Cycle: Perspective of Today's and Futuristic Human-System Interaction Environment
}

\author{
Mayank Pathak \\ Technocrats institute of \\ Technology, \\ Anand Nagar, Bhopal
}

\author{
Bhupendra Verma \\ Technocrats institute of \\ Technology \\ Anand Nagar, Bhopal
}

\author{
Ravindra Patel \\ Rajiv Gandhi Proudyogiki \\ Vishwavidyalaya \\ Airport Road, Bhopal
}

\begin{abstract}
With the latest innovations in the field of digital computing, communication and interconnecting technology, a new and of its own type of pervasive physical-digital ecosystem has started to emerge and in future it will be more ubiquitous, more dominant, more potent, more useful, more helpful, more usable. Finally, it will emerge as inevitable and indispensable part of our mundane interaction environment and everyday lifestyle experience. The designers, developers and practitioners of human-system interaction design have got a vital role to play in this transformation. The system development life cycle is the fundamental iterative reference cycle that specifies how to design and develop such technological systems. This work first focuses on those aspects which are of most significance from point of view of human-human concerns mediated by human-system interaction and are not appropriately addressed by canonical interaction-system development life cycle. This work then extends it along with specifying the realizing methodologies, in order to broaden the scope of the canonical system development life cycle to fulfil the present and future requisites in relation to people's interaction with the totality of ubiquitous environment in all respects.
\end{abstract}

\section{General Terms}

Software system development life cycle (SDLC). Humancomputer interaction.

\section{Keywords}

Software development life cycle, Ubiquitous computing, Human-system interaction (HSI).

\section{INTRODUCTION}

In future and even today also, the increasingly growing physical-digital intermingled ecosystem enriched with high quality digital devices connected in lightning speed network, progressively transforming itself the most sought after assisting and facilitating channel. Most of the services, commerce, applications, media, entertainment means, healthcare, insurance-services, financial services, banking, surveillance, information and knowledge assistance, hobbyfulfilling, job-finding and what not in almost every single respect for everyday experience are being ( and expected to be, if not today) offered in prime-association with digital technology $[1,2,3]$. This results in continuously increasing mass and massive compelling adoption of digital computing and communication technology by people throughout the world either due to need or due to desire [3]. Therefore, with the ever-increasing momentum towards exercise of ubiquitous computing environment into everyday practice, the notion of Human, Computer and Interaction from HSI (human-system interaction) perspective is required to be re-examined and redefined in the perspective of futuristic multi-useful ultrarich interaction environment [4]. The paradigm has now been shifted from 'what the computing technology can offer for us' to "what humans can do with computing and communication technology and how better in all respects it facilitates and presents its offerings to us under a larger and broader context of interaction environment and everyday experience' $[5,6]$.

In this scenario, the prevailing activity-centered and rolecentered approaches along with other traditional techniques for interaction-designing [1] under purview of present HSI discipline are not and will not be sufficient enough to cater the present and future requirements, aspirations and expectation of people. The focus should not be kept restricted towards optimizing the design of interactive interfaces only but it is to be broadened to optimize the design of interaction situations and environment in totality along with the development of superior interfaces. One step further, the scope of the interaction design under HSI must incorporate the digitaltechnology mediated post-deployment multidimensional impacts and ramification during interaction and beyond interaction on the human-human concerns, family-ties and social composition and also on various other stack-holders of society. These impacts may be short term or long term, direct or indirect, primary or derived, weak or strong. Even considering the present scenario of physical digital ecosystem, the most required, notable and essential aspect is how to address concerns related with cultural, social, organizational, ethical, human value $[1,4]$. In the process/attempts to evolve, evaluate and apply better methods, techniques and approaches seeking towards to shape society's new dynamic relationships with computing and communication technologies, the major challenge to appropriately address the questions like [7, 1, 4]

- How to help the designers and developers to comprehend and figure-out various problems faced by people with diversified nature and different range of abilities, information, attitude, knowledge, and skill-set?

- How to enable the designers and developers with design strategy/technique, technology and tool-sets to frame interactive information systems happen to be generalized from design point of view but personalized from use point of view? 
- How to support designers and developers in assessing the information systems with respect to people enriched with a wide and diversified range of abilities?

- What new codes of etiquette will need to be practiced and enforced with the use of information system in question with respect to a larger perspective and broader scope of technology mediated human-human concerns?

- What and how the new technologies, applications and services be designed to take all these into consideration?

In order to properly address all these questions and concerns, the solution path goes through modifying and extending the scope of design process of interactive systems. It is the need of the time to incorporate and ensemble the robust means in the design process of HSI systems that are focusing towards designing, evaluating or examining the scope of the system with respect to the diversified range of characteristics and abilities of people and investigate/facilitates the mechanism for adaptation of the interaction environment for catering people with diversified ranges of abilities. The prerequisite is that all such endeavours, in addition to fulfilling all existing criterions, must now focus and appropriately address broader set of concerns related most conspicuously with human values along with the moral and ethical aspects of designing systems, applications, services and technologies. Software-system's development life cycle (SDLC) is fundamental reference cycle and plays a pivotal role for developing such technological systems [8]. As per the traditional SDLC, any system is developed through exercising a predefined order of different successive phases in iterative fashion. Each phase has a specific aim and a predefined set of tasks is performed to attain that target. The iterative cyclic nature of the SDLC ensures that in order to improve the performance, as and when requirement comes any phase or set of phases can be revisited and revised.

Now, in order to enclose and cope up with all above discussed issues this paper proposes that one additional steps is required to be added and scope of the existing steps is required to be extended in the traditional canonical user-centered and activity-centered software-system's design and development life cycle, particularly targeting towards following:

(i) incorporating human-system interaction mediated human-human concerns and

(ii) enabling the users to get fit into various roles like creator, consumer, designer and likewise many more roles.

These additional improvements ensure creation, reinforcements and maintenance of attributes in human behaviour particularly pertinent to human values, societal/organizational/community-related issues and moral and ethical practices related concern. The additional step is incorporated in continuation with designing phase of SDLC for HSI systems and its impacts are rigorously examined during testing phase in light of facilitating worthy humansystem interaction in all relation.

As the environment around us increasingly happens to be efficient and effective along with the means of computing and communication, the importance of human system interaction (HSI or popularly known as human-computer interaction $\{\mathrm{HCI}\})$ increases manifolds. The next section discusses about a brief introduction of human system interaction discipline and assesses its scope in the light of present and future perspective. The Section-III then presents the redefined and extended SDLC. The last section spells-out the results and finally concludes the work.

\section{BACKGROUND}

The Special Interest Group on Computer-Human Interaction (SIGCHI) of the Association of Computer Machinery (ACM) defines Human Computer Interaction (HCI) as a discipline concerned with design, development, evolution, implementation and evaluation of interactive computing systems for human use, and with the study of major phenomena surrounding them [9]. The evolution of HSI (popularly known as HCI \{Human Computer Interaction\}) and its constituting interfaces is briefly summarized $[1,2,4$, $10]$ as follows.

Till around 1960 the user-interfaces were practically not present in computing systems. In 1963 first graphical user interface (GUI) and direct manipulation (DM) appeared through Sketchpad. Douglas Engelbart and William English demonstrated first mouse (control device) in 1968 through heir project 'Augmenting human intellect project'. In the same year, Engelbart presented so famous and groundbreaking system named 'NLS' with first to have functional provision of hypertext, multiple overlapping windows, on-screen video teleconferencing. Till now the focus of attention was technology. In 1970, some of the very good software came into practice and the field expanded its scope in terms of range of uses of computers and most importantly this field came out of laboratory practices to common practices although initially for skilled people.

This transformation slowly and steadily shifted the earlier technology-centric focus of attention towards user-centred design and this entire field emerged as new discipline referred as Human Computer Interaction (HCI) and got the momentum in 1980s. The HCI spotlighted for research on user-centered designs and methodologies with usability as a prime objective and technology as assisting role. During 1980s many commercial software packages came into play and WIMP along with DM interaction model/methods became very popular and widely employed in such systems. The importance of the interacting interfaces was firstly realized and in this decade new, highly useful and usable interaction styles, context menus, and devices like light pen, stylus, joysticks etc...were devised and widely used successfully.

In the next decade the HCI field expanded its scope in all its constituting parts- technological part, human part and interacting interfaces part. At technological end, it integrated theories, concepts and models from other allied fields like artificial intelligence, machine-learning, data-mining, patternrecognition in order to collectively propose the optimized solution of complex problems. At the other end in order to explore the human part, HCI looked forward towards some mature discipline related with understanding, explaining and predicting of human motor-processing activities, learning process, decision-making process, cognition, thought-process, human-response theory that are responsible for human behaviour, action and response. At the interacting interface designing level also intelligent and intuitive types of interaction metaphors, styles started to come on the floor.

In the late 1990s, the rapid developments and advancements in the field of electronic-mediated and tele-communication well supported by fast, small and accurate electronics hardware devices started to shape-up new and of its own kind regime of communication technology and soon these developments joined hand with chores of HCI domain. This entire phenomenon occurred in parallel and in conjunction 
with progressive advancements in integrated software development field in terms of new type of techniques, methods and approaches like object-oriented programming component-object based modelling, parallel programming and distributed-computing system architectures, enterprise planning, service oriented architectures, cloud computing and so on along with robust web-application development and integration tools. These were successfully applied for developing better system and application software. All these multidimensional, multifaceted progressions resulted in the emergence of new era of cohesive and/or coupled computing and communicative interaction environment in the mid of first decade of this century and it is still prevailing and flourishing.

We are and will increasingly be an integral part of a progressively growing conducive interaction environment which consistently happens to be tightly integrated, technologically embedded and finely immersed in surrounding physical space. This digital technology ideally aims to present the virtual environment of technological systems and solutions which is always on, always active and always accessible for everyone, almost for every use, at any time and at any place through an efficient computing, communicative and intelligently self-adaptive environment full of high quality miniaturised sensors connected in a highspeed network $[1,2,10,11]$. The speciality of this environment is that for end users, technology gets receded behind in the background and only utility component pops-up. This contemporary composition and constitution of advancements in this era matches with and aims (in many respects if not in all respects) towards realization of the conceptualization of Weiser's [12] vision for ubiquitous computing environment.

This era of ubiquitous computing, as originally envisioned by Weiser [12] transforming the world into digital-information society which is an active component of digital ecosystem and delimited through digital skyline [5]. This transformation opens ocean of opportunities and at the same time poses some serious challenges and problems also. Ideally, by virtue of being usable and useful for all and that too up to bottommost level, its scope of design, development and deployment happen to be extra-wide, extra-deep, extra-diverse, extrablended, extra-complex and importantly beyond engineering, science and technology framework. This condition arises due to the notable presence of several dimensions that are directly or indirectly involved, and the multiplicity of aspects in each such dimension.

One complex aspect, as per the Fischer [13] of designing of interactive systems is that the designers and developers have to build the information systems for the use of millions of targeted users considering varied possible purposes for which the system can be used while most importantly at the same time aiming towards creating clear perception in any individual user's mind at use time as if it were particularly developed by considering the characteristics of him/her. If this is achieved successfully then common problem of 'one-sizefits-all type of perception' [14] can be alleviated and large design spaces may be enabled to accommodate design restraints posed by diversity in the target user population. The major objectives in attempt to address broad and wide diversity are context-aware design; adaptable and adaptive interaction behaviour; personalized user-experience; efficient user modelling to address diverse user characteristics, requirements and expectations; cognitive and affective intelligence. Many designers, developers, researcher and practitioners $[3,7,10,13,14,15,16,17,18,19,20]$ have worked on these aspects of interaction designing in respect to ubiquitous computing environment.

The progressive realization of ubiquitous computing conceptualization in primary association with HSI discipline also raised a number of ethical, personal, cognitive, family and social concerns. If we look back then every now and then there were plentiful instances of nefarious, underbred, immoral and nagging type of misuse of the platform provided by digital technology. Over and above these pathetic concerns, in particular, it is also to be taken into account prudently and rationally that up to what extent the computing and communication technology are to be accommodated to play out crucial role in our everyday decision-making and planning activities? How and in what manner our abilities to perceive, learn, remember, analyse, think, problem-solving, skill-development and habit making/changing for ourselves as well as our physical well-beingness gets affected and suffers (if possible) as we rely increasingly on the computing and communicating environment to do the same for us? Moreover, looking for the efficient and balancing ways for the designers to decide that which set of activities is to be controlled by humans and which set of activities is to be left for environment to take over accountability for in an acceptable manner? [21]

Ultimately, considering today's and futuristic interaction scenario, HSI may not only be all about how better in every single respect people interact with particular devices under a particular context of use and for assortment of purposes. This scenario steers the researchers, designers and practioners towards extending the scope of human-system interaction domain in the discussed contexts. All the attempts in this direction branches out first to redefine and extend iterative system development life cycle being the fundamental reference cycle to design, developed, implement and maintain the information systems.

\section{PROPOSED WORK}

The thorough study, analysis of prevailing digital systems along with increasing real-time instances of misuse of technological systems points out that these technological advancements may pose severe threats towards individuals, family-ties, and furthermore the society in relation to safety, privacy, security, ownership, relationships etc. In long term perspective, it may also cause imbalance among different society constituents and adversely ruin family-ties and social composition. At individual level, it may lead users to be destructive, full of frustration and anti-social emotions/intentions. Only technological aid and means will not be sufficient enough to curb all these. Considering this scenario, this paper proposes that if the design and development cycle itself incorporates counter measures for above mentioned concerns right from the beginning, then the resultant systems will be much better and appropriately fit in all respects.

This work proposes the following interactive software's (may be application, services, solutions, products, systems) design and development iterative lifecycle consisting of six phases. Each phase has a well defined scope and predefined set of activities that are to be performed when that particular phase is realized during system development. All these phases with their domain of activities are explained as follows. 


\section{(i) Objective definition, requirement identifications and system analysis}

Whenever a new idea either to design an information system for a new opportunity or for enhancing some existing product/application/service is profoundly perceived then it becomes a considerable objective and preliminary concept proposal is framed. This proposal is reviewed for further refinements and a comprehensive objective description is finally outlined. This description includes specifying what types of people are under focus (target users) for this particular objective and in what sort of spheres of activities, areas of interests, surroundings, situations or cultures [22]. It also spotlight on the vigour that steer the people to connect with the proposed system, and on the means in which it can be presented and interweaved in the existing world. Even (if required), in order to aptly understand the overall system; its various and varied requirements; its usage environment; it may be broken down into different manageable modules or pieces. The ultimate aim is to deeply study and precisely define the superset of activities to appropriately answer

a) Why is this proposed system required? What is the overall requirement of it?

b) What is to be created and performed to fulfil the requirements identified?

c) Whom it is targeted for?

d) What benefits it is to be developed for?

e) What are the operating conditions, situations and environment?

This work proposes the extension here in this step. Now at this point, those social/organizational/cultural factors, human values and ethics are required to be identified and pinpointed that directly or indirectly get influenced, positively or negatively, by the resulting system and its by-products. Even sometimes, it may be the case that the scope of the object itself encompasses these and the demand, though peripherally, includes design for social connectivity, social signalling, collaborative environment, healthy communication, feeling of belongingness and togetherness- overall for the betterment of society. Overall, this extension will let choosing set of values, their nature and category the proposed system can offer, ignite, support, influence and reinforce.

Once the objective is well understood, defined and described then before proceeding further towards planning, detailed feasibility study is carried out to ensure the viability of a new or improved system in question. This takes mainly account of operational, economic, technical, legal and political feasibility. The proposed work here extends the scope of feasibility analysis to incorporate the social-acceptability, absorbability and fitness. This means the study and analysis of "how the proposed system, after deployment, will affect and alter the existing value system of the organization, community and society for which it is deployed and moreover what may be possible repercussions of these phenomenon".

The varied types of recourse-requirements (at first sight) for the project in question are also identified and fixed. The preliminary cost-benefit analysis and risk management aspects are addressed. If the results of all these are satisfactory then project management planning gets started. It includes firstly exhaustive analysing and understanding user needs, priorities, aspirations, preferences and expectations. Then detailed specifications of user requirements and functional requirements are well-documented from the perspective of project design and development team. An initial detailed timeline chart for project development and completion is framed.
Now the proposed system has thoroughly been understood from the different prospect and design of it is about to start. All the user requirements and functional requirements have properly been described. Here also we propose the extension in the scope of this step is that various stockholders of the developing project e.g. sponsors of the project, end-users, administrators, designers, and developers may be consulted in order to fix the set of values that as per their belief and experience come into force through the system in question. Even for this purpose, it is a better idea that further the experts from the other diverse disciplines like philosophy, psychology, cultural studies, anthropology, sociology and design are invited to contribute with their opinions, views, reflective thoughts, conceptual analysis and their findings and recommendations are to be forwarded to the designers and developers. This comprehensively escorts us to have solid understanding of how the human values of zest and user deportment/conduct are dynamically influenced and interplayed through proposed interaction environment, considering diverse social, environmental and situational factors and contexts. The ultimate aim is to understand and define how interaction mechanics supports and pursue the users for willingly adhering to long-lasting values through and beyond the interaction through the information system under development.

\section{(ii) Design and development}

In this phase the conceptual framework of the overall system is framed. This step covers in detail how, when and where different activities defined in step-I, will be realized in order to attain various goals/objectives of the overall system. It is this step that ensures the delivery of all predefined functionalities and features of the proposed system.

The designing phase includes the detail specifications of the operations and functions which are required to offer desired feature, their hierarchy-structure, various screen layouts, various standards, rules and norms in the context of application in question, process diagram (entity relationship diagrams, data flow diagrams, and control flow diagrams), complete data dictionary and other relevant documents. If the overall system was broken down into different modules then this step defines all issues related to how individual module behaves, how these modules are to be interconnected; how these modules interact to each-other; how results of individual modules are assembled as overall complete system.

The development phase includes the development of paper prototypes, sketches, test-cases designing, use-case designing, structuring databases table and file, specifying system environment (e.g. development, integration, testing and deployment environment).

The proposed work emphasizes on that the human interacting interfaces should be perceived, treated, developed (or modify the existing-one) and/or plugged-in as a separate entity during the software development life cycle. For this to achieve, the protocols may be set for standardizing the connections between interface and rest of the software and the 'glue-code' can be defined as per those protocols. This will make possible for the independent or third-party vendors to come into role and offer their more innovative, productive, useful and usable interfaces. These third-party solutions may be made more customizable and therefore may be more acceptable to the users. For this to realize practically there should be proper balance between personalization and standardization because at first sight, they seems to be 'conflicting' to each-other. More the standardization of the process would be, lesser the 
scope and possibility left for personalization. The developer demands for more standardization because then it becomes easy for them to write the code by adhering to the standards and further this facilitates the compatibility of one service or product with the other. On the contrary, the end-user demands for more personalization to interact through customizable interfaces. Therefore proper trade-off should be managed between the two and this work proposes the following approach:

"The technological integration and interconnection part should be standardized i.e. norms and protocols must be specified interconnecting the services, products, components, devices and furthermore making them compatible to oneanother. On the contrary, the presentation part (that directly interact with the people) of these services, devices, applications or products are to be designed appropriately flexible and customizable in such a manner so that the endusers can personalize them as per their own characteristics, preferences, interests and convenience, This refers to proper ethnography process i.e. looking at particular kinds of people in particular contexts".

Now from the HSI perspective, this stage of design and development includes developing a thoughtful understanding of when, where and what factors may be at play and how to devise the system so that it incorporates the mechanism for the values of interest (identified in first phase) to be manifested, reinforced, practiced, strengthened and persuade. For this to achieve the canonical approach has to widen its scope to look beyond individual's interaction or set of practices around the designated objective in order to focus on allied targets of inculcating, enforcing and strengthening human values contributing towards social/organizational/community growth also, through and beyond the interaction experience. The designer should just not keep in mind people's interactions with digital technology, but also focus at their natural interactions with the day-after-day world more broadly with respect to the environment, everyday objects, other people and embedded hi-tech elements.

It is obvious that all these are particular higher-level values which are always reflected and manifested in the specific behaviour of individuals during and beyond interaction. Therefore at design and development time, various possible interacting scenarios, cases, situations, environments must be taken into account under the light of technological, social, organizational, family, and cultural parameters. This is a obviously a more complex activity, inviting inputs from allied disciplines of HSI. This may even require user and use-case study of one type or another. This facilitates with proper blend of perspective and insights within the scope of which various technological potentials and possibilities can be appropriately envisaged and outlined.

\section{(iii) Outcomes assessment and appraisal:}

This is new step that the proposed work presents to introduce into the SDLC. It mainly focuses upon the assessment of extra-engineering aspects of the system in question. This is very important activity in view of extended scope of SDLC. It lets the appraisal of the design and development work outcome with respect to two dimensions. These dimensions are as follows.

\section{(1) Moving beyond engineering:}

The concepts of usability, accuracy and efficiency have now become less important and significant as prime objective is now to design and weave an interaction environment and user experience that is superior in many more contexts other than engineering aspects. There is a rich set of techniques, methods and approaches through which the outcome of the previous phase can be assessed and appraisal report can be prepared $[23,24]$ in relation to the criterion like usability, accuracy and efficiency.

\section{(2) Guidance-cum-verification from interaction analyst}

It assesses the interaction environment and experience against human values of interest that whether it is able to enable and enforce the desired value system. For this use-case studies and user studies can be conducted. They allow inspecting the ways in which specific types of human behaviours interplay with set of specific values of concern. This type of analysis is a complex analysis and requires concepts and theories of other allied disciplines like philosophy, human-psychology, sociology, art and design etc. Further user-studies can be performed and test-cases can be run in the laboratory within controlled environment in order to proper investigate the situations and manner in which specific type of human behaviours and responses interplay with specific values of interest.

With this appraisal, it is concluded that whether the proposed system helps individuals as users, consumers, designers and practitioners in developing the desired characteristics and values with respect to their individual needs and desire to do so as well as with respect to societal, organizational, environmental context in prevailing physical-digital ecosystem.

One important thing about this phase is that the third party verification through team of experts or analysts can be asked in order to authenticate the claimed outcomes.

\section{(iv) Coding, implementation and integration}

In this phase the various design layouts, screen-layouts, databases, test-case procedures, test files are prepared/created/coded, implemented, compiled and executed (may be in modular and hierarchical structure). In this process various alternatives are tried and the best optimized approach and technology is applied after refinements (if required). At last, finally all these individual segments of solution are integrated and properly interfaced into a complete targeted information system.

\section{(v) Test}

This is performed for quality assurance whether the developed system conforms to user and functional requirements as specified in the earlier steps. This may include on-site and offsite testing. Detail test reports are prepared.

The test and evaluate phase also includes the assurance that when the developed system deployed within operational environment and afterwards practiced by various stackholders, then it functions in an expected manner and it also creates and maintains the working environment as envisioned in previous phases in the light of values of interest like safety, ownership, security, transparency, equality etc...

This phase also includes in its scope to ensure that all the stockholders happen to be satisfied, delightful, convinced and able to use all desired/required functionalities in personalized way and possibility of malfunctioning are minimized. 


\section{(vi) Operation and maintenance}

Proper user training (if required) is provided regarding knowing prerequisite of the system, how to fully operate and optimally use the system. At the same time support staff training is to be given for proper maintenance (post deployment issues). Finally the system is deployed in production operating environment.

The Table 1 summarizes various phases of the proposed SDLC with respect to extension in scope, tasks and other dimensions.

Table 1. Summary of proposed iterative SDLC

\begin{tabular}{|c|c|c|c|}
\hline Phases & Additional Revised Scope & Prime Activities & $\begin{array}{l}\text { Supporting Methods or } \\
\text { Entities }\end{array}$ \\
\hline $\begin{array}{l}\text { Objective definition, } \\
\text { requirement } \\
\text { identifications and } \\
\text { system analysis }\end{array}$ & $\begin{array}{l}\text { Extended for technology- } \\
\text { mediated Human-human } \\
\text { concerns w.r.t. social/ } \\
\text { organizational/cultural factors }\end{array}$ & $\begin{array}{l}\text { - Deep and thoughtful analysis of objective, } \\
\text { its requirement identification and solution } \\
\text { system analysis } \\
\text { - Feasibility study } \\
\text { - Determination of user and functional } \\
\text { requirements } \\
\text { - Involve the experts from allied discipline } \\
\text { and getting their advices and in case of } \\
\text { many alternatives seeking their advocacy } \\
\text { - Identification of the values and factors that } \\
\text { significantly may come into play }\end{array}$ & $\begin{array}{l}\text { - Experts form allied } \\
\text { discipline of Human- } \\
\text { system interaction like } \\
\text { human psychology, } \\
\text { philosophy, sociology } \\
\text { etc. }\end{array}$ \\
\hline $\begin{array}{l}\text { Design and } \\
\text { development }\end{array}$ & $\begin{array}{l}\text { When, where and how values } \\
\text { and factors come into play } \\
\text { during and beyond interaction } \\
\text { How the proposed system } \\
\text { incorporate the mechanisms to } \\
\text { ignite, promote, reinforce, } \\
\text { strengthen the values of } \\
\text { interest }\end{array}$ & $\begin{array}{l}\text { - Preparation of Screen lay-outs, } \\
\text { components hierarchical structure, process } \\
\text { diagrams } \\
\text { - Preparation of Paper prototypes, use-case } \\
\text { and test-case designing, database table } \\
\text { preparation } \\
\text { - includes the mechanisms to strengthen the } \\
\text { positive values and suppress the negative } \\
\text { values }\end{array}$ & $\begin{array}{l}\text { - Experts from art, } \\
\text { ergonomics, } \\
\text { conventional design and } \\
\text { interface design } \\
\text { - Isolate the interacting } \\
\text { interfaces with rest of the } \\
\text { software system from } \\
\text { designing perspective }\end{array}$ \\
\hline $\begin{array}{l}\text { Outcomes } \\
\text { assessment and } \\
\text { appraisal }\end{array}$ & $\begin{array}{l}\text { Thinking about and } \\
\text { investigating } \\
\text { engineering aspects and } \\
\text { assuring the fitness of the } \\
\text { proposed system w.r.t. social, } \\
\text { physical, environmental, } \\
\text { cultural, moral, ethical and } \\
\text { other pertinent aspects }\end{array}$ & $\begin{array}{l}\text { - Asking the experts form engineering and } \\
\text { allied disciplines to assess and appraise the } \\
\text { outcomes of previous phase } \\
\text { - Third party authentication/ verification } \\
\text { may be asked }\end{array}$ & $\begin{array}{l}\text { - Mock-test experts } \\
\text { - User study under } \\
\text { controlled environment } \\
\text { - Theories and models } \\
\text { from mature discipline } \\
\text { like sociology, } \\
\text { psychology, philosophy }\end{array}$ \\
\hline $\begin{array}{l}\text { Coding, } \\
\text { implementation and } \\
\text { integration }\end{array}$ & $\begin{array}{l}\text { Third party vendor may be } \\
\text { entertained for interface } \\
\text { designing part and if possible } \\
\text { then some such tools may be } \\
\text { provided directly to the users } \\
\text { that enable them to design and } \\
\text { customize the interacting } \\
\text { interface themselves } \\
\text { according to their own choices }\end{array}$ & $\begin{array}{l}\text { - Technologically solutions are coded, } \\
\text { implemented for different modules and } \\
\text { finally they are packaged in one solution }\end{array}$ & $\begin{array}{l}\text { - Existing technologies, } \\
\text { frameworks, platforms } \\
\text { and packages }\end{array}$ \\
\hline Test & $\begin{array}{l}\text { Conformity of the final } \\
\text { system is examined against } \\
\text { engineering and extra- } \\
\text { engineering concerns }\end{array}$ & $\begin{array}{l}\text { - Test cases are exercised through the } \\
\text { developed systems } \\
\text { - Includes various type of testing practices } \\
\text { (may be onsite testing also) }\end{array}$ & $\begin{array}{l}\text { - Experts from allied } \\
\text { disciplines } \\
\text { - Existing software } \\
\text { engineering testing tools } \\
\text { and methods }\end{array}$ \\
\hline $\begin{array}{l}\text { Operation and } \\
\text { maintenance }\end{array}$ & $\begin{array}{l}\text { Time to time examine the } \\
\text { impacts, implications and } \\
\text { outcomes of deployed system } \\
\text { particularly in the context of } \\
\text { ongoing social, moral and } \\
\text { ethical concerns. Make some } \\
\text { amendments if required }\end{array}$ & $\begin{array}{l}\text { - Proper user and maintenance-staff training, } \\
\text { deployment of the developed system in } \\
\text { operating environment } \\
\text { - As and when required resolve the } \\
\text { technology or use generated issues and } \\
\text { release the patches/checks/solutions/ } \\
\text { upgraded versions }\end{array}$ & $\begin{array}{l}\text { - Designer, developer and } \\
\text { maintenance contractor } \\
\text { of the deployed system }\end{array}$ \\
\hline
\end{tabular}




\section{RESULTS AND CONCLUSION}

Today, the highly popular window on system's screen remains no longer the only window to interact with increasingly growing virtual digital world. At the same time, the ambience all around us is becoming more proactive, more helpful, more useful, more powerful, more usable and more intelligent with the immersive integration of high quality possible miniaturized array of smart devices, sensors, objects enriched with more natural, intuitive and customizable interfaces. This environment is and progressively will be facilitating human life and life-style with consistently upgraded superior high-class computing and communication services. This advancement also poses some serious problems and challenges of varied nature and scale at various levels for different stack holders of this ambience. The technology mediated human-human issues are of utmost importance. This entire scenario promotes for the HSI to redefine and broaden its scope, being the prime concerned discipline.

In this above perspective, this paper presents an extended iterative system development life cycle for realizing the systems that are not only offering services to the people in a better way but encompasses and addresses technology mediated human-human concerns also. The revised first phase ensures that all the implications and reflections of proposed information system are identified and pinpointed in a broader perspective including personal, social, and cultural aspects. The extended second phase points out that where, when and how the values and factors come into play. It includes the mechanisms to strengthen the positive values and suppress the negative values. Lastly, a newly added phase-III assesses and appraises about the proposed set of outcome with respect to pre-identified parameters

Initially it may seem that adding one more phase and extending the scope of the other phases of the canonical SDLC will increase the design and development time but in longer perspective it will reduce the chances of revisiting, redesigning or revising the entire system or a part of it. The information systems, designed with this proposed SDLC, definitely helps to create, maintain and sustain a healthy human-computer interrelationship under larger and broader scope of diversified contexts. They support the people to live a highly facilitating life-style and be an integral part of the digital ecosystem with a close perception of value like satisfaction, safety, security, ownership, transparency, equality and many more.

The presented work particularly focuses on need to involve and associate experts from the allied disciplines of HSI to design and assesses the systems from human psychological, philosophical, physiological, and sociological point of view in addition to the engineering point of view. In future, we expect that more concepts, theories, approaches and models will emerge as a result of this partnership and moreover, it leads towards an efficient and enriched environment well-accounted for establishing and managing a proper balance among our formal, informal, personal and social lives.

\section{REFERENCES}

[1] Carroll, J.M. 2008. Human-Computer Interaction, Second Impression. Pearson Education.

[2] Sharp, H., Rogers, Y. and Preece, J. 2007. Interaction Design: beyond Human Computer Interaction, Second Edition. Wiley India.
[3] Pathak, M., Verma, B. and Patel R. 2012. Intertwining Cognitive and Affective Intelligence into Digital Artifacts: An Infrastructural Approach. IEEE Proceedings of 4th International Conference on Intelligent Human Computer Interaction, 1-7

[4] Richard Harper, Tom Rodden, Yvonne Rogers and Abigail Sellen (Editors), 2008 Being Human: HumanComputer Interaction in the year 2020, Publisher: Microsoft Research Ltd

[5] Chang, E., Dillon, T., and Calder D. 2008. Human System Interaction with Confident Computing: the Mega Trend. International Conference on Human System Interactions (HSI), 1-11.

[6] Wakkary, R. and Maestri, L. 2008. Aspects of Everyday Design: Resourcefulness, Adaptation, and Emergence. International Journal of Human-Computer Interaction, 24(5), 1-14.

[7] Biswas, P., Robinson P. and Langdon P. 2012. Designing Inclusive Interfaces through User Modeling and Simulation. International Journal of Human-Computer Interaction, 28(1), 1-33.

[8] Pressman, R. S. 2010. Software Engineering: A practitioner's Approach, Mc GRAW HILL International Edition.

[9] Rusu, C., Rusu, V., and Roncagliolo, S. 2008. Usability Practice: The Appealing Way to HCI. 1st International Conference on Advances in Computer Human Interaction, 265--270.

[10] Ehlert, P. 2003. Intelligent user interface: introduction and survey," Research Report DKS03-01 / ICE 01, Version 0.9.

[11] Pathak, M., Patel, R. and Verma, B. 2010. Framework for effective and efficient communication using intelligent and adaptive interfaces, Second IEEE International Conference on Intelligent Human Computer Interaction (IHCI 2010) Allahabad, India, 115-120.

[12] Weiser, M. 1991. The Computer for the 21st Century. Scientific American. 265, Nr. 3, 94-101.

[13] Fischer, G. 2001. User Modeling in Human-Computer Interaction. User Modeling and User-Adapted Interaction, 11, 65-86.

[14] Zhang, J. \& Ghorbani, A.A. 2007. GUMSAWS: A Generic User Modeling Server for Adaptive Web Systems. Fifth Annual IEEE Conference on Communication Networks and Services Research. 117124.

[15] Korth, A., and Plumbaum, T. 2007. A Framework for Ubiquitous User Modeling. IEEE International Conference of Information Reuse and Integration, 291297.

[16] Leonidis, A., Antona, M. and Stephanidis C. 2012. Rapid Prototyping of Adaptable User Interfaces. International Journal of Human-Computer Interaction, 28(4), 213-235.

[17] R. W. Picard, E. Vyzas, and J. Healey. 2001. Towards machine emotional intelligence: analysis of affective physiological state, IEEE Transaction on Pattern Analysis and Machine Intelligence, vol. 23, No. 10, $1175-1191$. 
[18] J. Liu and H. Ando. 2008. Emotion eliciting and decision making by psychodynamic appraisal mechanism, International Conference on Human System Interaction (HIS), Kralow, Poland, 645-650.

[19] Chee Kit Yee, Choo Seah Ling, Wong Seok Yee, and Wan Mohd Nazmee Wan Zainon. 2012. GUI design based on cognitive psychology: theoretical, empirical and practical approaches. 8th International Conference on Computing Technology and Information Management (ICCM), vol. 2, 836 - 841 .

[20] Calvo, R. A. and D'Mello, S. 2010. Affect Detection: An Interdisciplinary Review of Models, Methods, and Their Applications, IEEE Transactions on Affective Computing, Vol. 1, No. 1, 18-37.

[21] Rogers, Y. 2006. Moving on from Weiser's Vision of Calm Computing: Engaging UbiComp Experiences,
Ubicomp 2006, LNCS 4206, Springer-Verlag Berlin, 404 $-421$

[22] Guida, G. and Lamperti, G. 2000. AMMETH: A Methodology for Requirements Analysis of Advanced Human-System Interfaces, IEEE Transactions on Systems, Man, and Cybernetics-Part A: Systems and Humans, Vol. 30, No. 3, 298-321.

[23] Chang, E., and Dillon, T. S. 2006, A UsabilityEvaluation Metric Based on a Soft-Computing Approach, IEEE Transactions on Systems, Man, and Cybernetics-Part A: Systems and Humans, Vol. 36, No. 2, 356-372.

[24] Brinkman, W.P., Haakma, R., and Bouwhuis, D.G. 2008. Component-Specific Usability Testing, IEEE Transactions on Systems, Man, and Cybernetics-Part A: Systems And Humans, Vol. 38, No. 5, 1143-1155. 